\title{
To peck or not peck: Which do pigeons prefer?
}

\author{
Danielle M. Andrews ${ }^{1} \cdot$ Thomas R. Zentall ${ }^{1}$ \\ Published online: 12 November 2018 \\ (C) Psychonomic Society, Inc. 2018
}

\begin{abstract}
Animals are expected to minimize time and effort to reinforcement. Thus, not pecking should be preferred over pecking. However, even if time is held constant, pigeons often peck when it is allowed but not required (e.g., fixed time schedules), but with such schedules pecking may be adventitiously reinforced. In the present experiment, to better compare a schedule of reinforcement that requires pecking with one that requires the absence of pecking, we compared a modified fixed-interval (FI) schedule in which reinforcement follows the first peck after the interval has elapsed and a differential-reinforcement-of-other behavior (DRO) schedule, which requires pigeons to abstain from pecking for a similar interval. The delay to reinforcement was matched on a trial-by-trial basis by yoking the duration of the FI to match the DRO schedule that preceded it. Of 12 pigeons, six preferred the DRO schedule over the FI schedule and six did not show a schedule preference. Those that were indifferent between the schedules apparently had a stronger spatial preference than their schedule preference. Individual differences in the preference of the pigeons may have been related to their behavior during the DRO schedule.
\end{abstract}

Keywords Pecking $\cdot$ Not pecking $\cdot$ Differential reinforcement of other behavior $\cdot$ Choice $\cdot$ Pigeons

\section{Introduction}

If pigeons are given a choice to peck or to refrain from pecking they should prefer to refrain from pecking because pecking requires both time and effort; also, it is well established that pigeons have a strong preference for immediate reinforcement over delayed reinforcement (Ainslie, 1975). Furthermore, if delay to reinforcement is held constant, the principle of least effort suggests that animals should minimize effort (Gengerelli, 1930; Tsai, 1932; Waters, 1937). However, even if time is held constant, pigeons often peck when it is allowed but not required (sign-tracking; Hearst, 1987). And pigeons sometimes persist in pecking even when pecking prevents reinforcement altogether (omission; Williams \& Williams, 1969). Hearst (1987) suggested that this sign-tracking behavior appears to be under the control of Pavlovian processes. There is even evidence that animals will continue to work for food even when identical free food is available from a nearby dish (contra-freeloading; see Inglis, Forkman, \& Lazarus, 1997 for a review).

Thomas R. Zentall

zentall@uky.edu

1 Department of Psychology, University of Kentucky, Lexington, KY 40506-0044, USA
There remains a tendency to view responding as a cost of obtaining food. For example, in the suboptimal choice or gambling paradigm, pigeons show a preference for a $20 \%$ chance of signaled reinforcement over a $50 \%$ chance of unsignaled reinforcement (Stagner \& Zentall, 2010; see Zentall \& Laude, 2013 for a review). Recently Hinnenkamp, Shahan, and Madden (2017) tested the hypothesis that non-reinforced pecking is responsible for avoidance of the optimal choice with this procedure. They tested the hypothesis that when pigeons choose the alternative with $20 \%$ signaled reinforcement, pecking the signal for reinforcement is always reinforced and they rarely peck the signal for the absence of reinforcement, whereas when they choose the $50 \%$ unsignaled reinforcement alternative, pecking is reinforced only $50 \%$ of the time. Thus, pecking the $50 \%$ unsignaled reinforcement alternative is often not reinforced, and they suggest that those unreinforced pecks to the signal for 50\% reinforcement may result in a preference for the suboptimal alternative. Hinnenkamp et al. found, however, that the rate of nonreinforced pecking did not predict the preference for the suboptimal alternative. Although in this experiment the rate of non-reinforced pecking did not appear to influence choice, it is clear that the influence of response rate on choice is still a relevant issue.

Assessing the preference between two schedules requires the use of a procedure that separates schedule choice from the 
schedule itself. The concurrent chains procedure provides a measure of choice between two alternatives by allowing entrance into the terminal link, the schedule of interest, to be determined by identical initial-link schedules (Herrnstein, 1964).

Using a concurrent chains schedule to test the avoidance of pecking, Killeen (1968) encouraged pigeons to vary their response rate. He recorded choice between one alternative (left) that encouraged pecking using a 30-s variable-interval (VI 30s) schedule, in which one response was required after a variable amount of time, and another alternative (right) that discouraged pecking (a VI 30-s schedule that only provided reinforcement if the pigeon refrained from pecking during the last $1.5 \mathrm{~s}$ of the interval). The manipulation was effective in producing different rates of pecking. On average 52.3 pecks/ min were made on the left (VI) key and 0.95 pecks/min were made on the right (VI no peck during last $1.5 \mathrm{~s}$ ) key. Despite the difference in response rates, the pigeons were indifferent with regard to the two alternatives. However, the no peck contingency during the last $1.5 \mathrm{~s}$ of the interval typically extended the delay of reinforcement in that alternative, compared to the standard VI 30-s schedule, thus possibly reducing the preference for the low-response-rate schedule.

Fantino (1968) also investigated the influence of response requirements on choice. For one group of pigeons, one terminal link required a high rate of responding (differential-reinforcement-of-high-rate (DRH) with no fewer than $n$ responses in $t \mathrm{~s}$ ), while the other terminal link required only one response after a fixed duration (fixed-interval, FI). The second group of pigeons experienced one terminal link that required a low rate of responding (differential-reinforcement-of-low-rate, DRL, with no more than $n$ responses in $t \mathrm{~s}$ ), while the other terminal link was an FI schedule. The FI schedule was manipulated to provide the same proportion and rate of reinforcement as the DRH or DRL on the prior session.

Fantino (1968) found that pigeons preferred the FI schedule, the schedule with the lower response requirement, over the high-rate (DRH) schedule. He suggested that the response requirement influenced choice beyond the rate of reinforcement alone. However, the DRH requires pecking at a high rate and that may be aversive to the pigeon, independent of pecking itself. There were mixed results for the FI/DRL group; two birds were indifferent and the third one preferred the FI schedule.

Moore and Fantino (1975) later attempted to control for the delay to reinforcement, as well as rate of reinforcement, by comparing a response-dependent schedule (variable-interval, VI) and a response-independent schedule (variable-time (VT) schedule; reinforcement was provided after the passage of a variable amount of time, independent of pecking) by using comparable inter-reinforcement intervals between schedules. In the VT schedule, the response rate is allowed to vary without control. Moore and Fantino found that the response rates were lower in the response-independent (VT) schedule than the response-dependent (VI) schedule, but the pigeons were indifferent between the two schedules. However, given that the pigeons pecked at a moderate rate during the VT schedule, the difference in peck rates may not have been large enough to produce a differential preference. Brinker and Treadway (1975) also found indifference between a VI schedule and a VT schedule in Asian quail. Although one bird showed a preference for the VI schedule, the remaining three birds did not show a consistent preference.

Similarly, Neuringer (1969) found that there was no differential preference between an FI and FT schedule when interreinforcement intervals were held constant. But the FT was a period of blackout that may have biased the animals against that alternative (see also, Davison, Alsop, \& Dennison, 1988). Also, in Neuringer's experiment the initial links were 90-s VI schedules with a 1.5-s delay if the bird switched keys while responding (a 1.5-s changeover delay (COD)). A problem with the use of VI schedules in the initial link is the time to enter the terminal link will vary from trial to trial and local biases may result. One way to avoid the problem of local differences in the time to enter the terminal links is to require only a single response to the initial link.

As part of a larger study, Singer, Berry, and Zentall (2007) compared pigeons' concurrent chains preference for pecking or not pecking (by using a differential-reinforcement-of-otherbehavior (DRO) schedule; not pecking the response key) over required pecking (fixed interval (FI)). They did this under conditions that controlled for the delay to reinforcement on a trial-by-trial basis by matching the duration of FI trials to the duration of the DRO trials. The experiment was designed to use the expected preference for the DRO schedule to decrease the pigeons' preference for the stimuli that followed that schedule (a justification of effort effect; Clement, Feltus, Kaiser, \& Zentall, 2000). Of the seven pigeons tested, four were indifferent with regard to the two schedules, one preferred the FI schedule, and two pigeons preferred the DRO schedule. Thus, most pigeons did not prefer to avoid pecking and one actually showed a preference for pecking.

The purpose of the Singer et al. (2007) experiment was to create trials of equal duration, to determine if the subjects had a preference for the stimulus that followed each of the schedules. The purpose of the present experiment was to more directly investigate relative schedule preference between a DRO and FI schedule in which schedule duration was controlled by yoking the schedules on a trial-by-trial basis. In the present research we asked if pigeons have a preference for pecking or refraining from pecking, controlling for delay to reinforcement. To do this, we compared a pigeon's preference between a schedule associated with pecking (FI) and a schedule associated with the absence of pecking (DRO) for a comparable duration (Herrnstein \& Morse, 1957; Reynolds, 1961). If the pigeon pecked during the DRO trial, the timer reset the 
interval and the pigeon had to refrain from pecking the full assigned duration to receive reinforcement. To equate for delay to reinforcement, we used a yoked FI schedule, such that if pecking occurred during the DRO schedule, the subsequent FI schedule was extended to match the duration of the two schedules on a trial-by-trial basis. Preference for the DRO schedule would suggest that the pigeons preferred to refrain from pecking.

In Phase 1 of the experiment, we compared a pigeon's preference between reinforcement schedules using spatiallydefined concurrent chains (access to the FI schedule on one side key, access to the DRO on the other side key, with spatial location of the two schedules counterbalanced over subjects). In Phase 2, the spatial location of the two chains was reversed to determine if the pigeons would switch location to follow what appeared to be their preferred schedule. In Phase 3, we used a visual discrimination on the initial link to determine if the subjects would follow the initial link stimulus associated with their preferred schedule as it switched from side to side over trials.

A preference for the DRO schedule over the fixed-interval schedule would be consistent with the principle of least effort (Gengerelli, 1930; Tsai, 1932; Waters, 1937) as well as previous research (Fantino, 1968). A preference for the FI schedule over the DRO schedule would suggest that pigeons prefer pecking rather than being required to refrain from pecking. In an FI schedule, a peck is required immediately before reinforcement and the association of that peck with reinforcement could actually result in a preference for pecking (as Singer et al., 2007, found for one pigeon). The FI schedule may also be preferred because, although the schedules are equated for their duration, pecking has been found to result in the subjective speeding up of the passage of time (Zentall \& Singer, 2008). That is, pigeons have been shown to underestimate the passage of time when they are satisfying a pecking requirement relative to when they are required to refrain from pecking. Indifference between schedules would suggest that the delay to reinforcement, rather than the response requirement, controls schedule preference.

\section{Method}

\section{Subjects}

The subjects were 12 non-naïve, White Carneau, unsexed pigeons that had participated in unrelated simultaneous color discrimination learning experiments. All subjects were retired breeders from the Palmetto Pigeon Plant (Sumter, SC). During the experiment, the birds were kept at $85 \%$ of their freefeeding body weight. Grit and water were available to the birds at all times in their individual home cages $(28 \times 38 \times$ $30.5 \mathrm{~cm})$. The home cages were located in a climate- controlled room on a 12-h light-dark cycle and cared for in accordance with University of Kentucky Animal Care Guidelines.

\section{Apparatus}

The experiment took place in a standard LVE/BRS (Laurel, MD) test chamber measuring $36 \mathrm{~cm}$ high $\times 30 \mathrm{~cm}$ from the response panel to the back wall $\times 36 \mathrm{~cm}$ across the response panel. The pigeons responded to three response keys $18 \mathrm{~cm}$ above the floor, $2.5 \mathrm{~cm}$ in diameter, and $6 \mathrm{~cm}$ apart on the response panel. Behind each key was a 12-stimulus inline projector (Industrial Electronics Engineering, Van Nuys, CA) that projected one of five stimuli (white, red, green, blue, and yellow for one group, white, vertical lines, green, blue, and yellow for the other group) onto the response keys. A center-mounted feeder located $10 \mathrm{~cm}$ above the floor, which, when raised, was illuminated by a $28-\mathrm{V}$ 0.04-A lamp, allowed access to mixed grain for reinforcement. White noise was generated from outside the chamber and the apparatus was controlled by a computer in the adjacent room running MedPC IV (Tatham \& Zurn, 1989) with a 10-ms resolution.

\section{Procedure}

Trials were organized in triplets (three trial blocks). Each triplet began with a forced DRO trial, followed by a forced modified (yoked) FI trial of matched duration. The third trial in the sequence allowed a choice between the two preceding equal duration schedules. Each session consisted of 20 triplets ( 60 trials). Pigeons experienced one session per day, 6 days a week.

The experiment involved a concurrent chains procedure. At the start of each trial a white orienting stimulus was presented on the center key. The orienting stimulus was used to ensure the bird's head was equidistant from either side key. Following a single peck to the center key, one side key was illuminated. The side key was the initial link for the forced DRO trial. Following one response to the side key, the key changed color to initiate the forced DRO 10-s schedule. Any response to the illuminated response key reset the timer to 10 s. Once $10 \mathrm{~s}$ elapsed without response, $2 \mathrm{~s}$ of access to mixed grain via the food hopper was provided. Following reinforcement, there was a 3-s house-lit inter-trial interval.

The next trial was a forced (yoked) FI trial matched in duration to the previous DRO trial. It started with the orienting stimulus on the center key. Following a single peck to the center key, the other side key was illuminated. The first response after a duration equal to the duration of the preceding DRO trial was reinforced with $2 \mathrm{~s}$ of access to mixed grain.

The third trial in each triplet was a choice trial in which after the observing response to the center key, both side keys were illuminated with discriminative stimuli allowing the 
birds to make a choice between the DRO schedule and the FI schedule. One response was required to change the color from the initial link to the terminal link of the selected key and darken the unselected key. Pecks to darkened keys had no effect. Each experimental session provided 60 reinforcements.

Pre-training To facilitate acquisition of the DRO contingency, the terminal link DRO duration started at $1 \mathrm{~s}$ and was gradually extended to $10 \mathrm{~s}$ on the side key that would serve as the DRO key. FI trials of equal duration were interspersed on the other side key.

Phase 1: Spatial discrimination The fixed location of the FI and DRO contingencies was randomly determined for each pigeon and was signaled by a distinctive stimulus. For one group, the FI schedule was signaled by a vertical line initial link stimulus followed by a green terminal link stimulus on the right side. The DRO schedule was a blue initial link stimulus followed by a yellow terminal link on the left side. For the other group, the DRO schedule was signaled by a red initial link followed by a green terminal link on the right side, while a blue initial link followed by a yellow terminal link on the left side signaled the FI schedule (see Fig. 1). Although we considered the discrimination to be spatial, the discrimination could also have been based on the color of the (redundant) initiallink stimulus. Phase 1 consisted of 22 sessions.

Phase 2: Reversal of the spatial discrimination In Phase 2, the spatial location of the two schedules and their accompanied stimuli was reversed. The reversal was included to determine if the schedule preferences found in Phase 1 might have

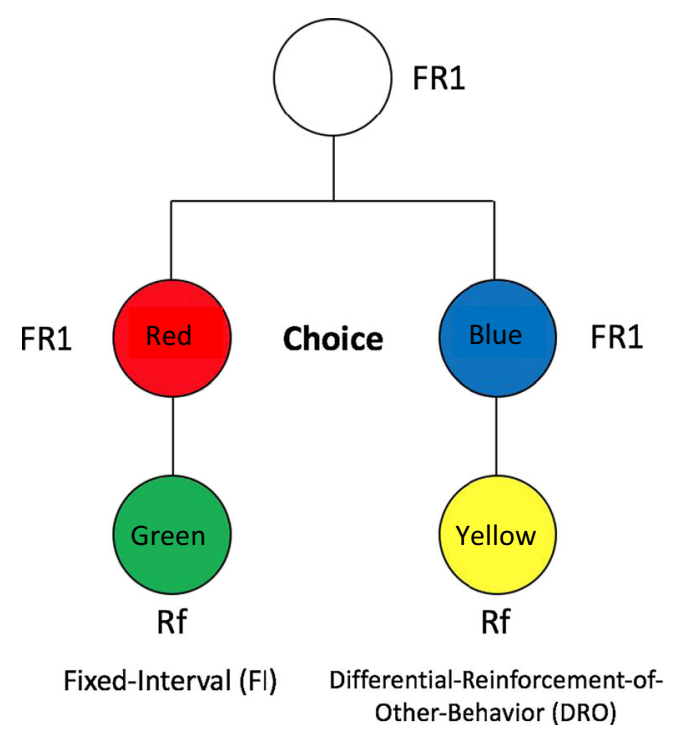

Fig. 1 The concurrent chains design. For half of the pigeons the red initial link consisted of black and white vertical lines resulted solely from spurious spatial preferences unrelated to the schedules. Phase 2 consisted of 15 sessions.

Phase 3: Visual discrimination In Phase 3, the visual initial link stimuli remained predictive of the terminal link stimuli and schedules that followed but those stimuli together with the schedules that they predicted were randomly alternated from side to side (i.e., the spatial cues were no longer relevant). Phase 3 consisted of 28 sessions. On session 29, each pigeon's behavior was observed by the first author in the presence of the two schedules.

\section{Analyses}

For purposes of statistical analyses, the last ten sessions of each phase were used to ensure stable performance and exclude variation due to initial learning. Session data were based on means of the trial-by-trial data.

Preference was of primary interest and determined by the number of DRO choices out of 20 possible choice trials. Choice data were analyzed for changes over the three testing phases using a repeated-measures analysis of variance.

The duration of the DRO schedule links, the number of times the DRO timer was reset, the number of pecks made during the FI schedule, and the number of times the DRO alternative, as opposed to the FI alternative, was chosen on choice trials (DRO choice) was recorded and analyzed using Pearson correlations. Statistical significance was set at the $p=$ .05 level for all statistical tests.

\section{Results}

An independent-samples $t$-test was conducted to compare mean DRO schedule preference between counterbalance groups for the average of all phases (Group $1 M=64.2 \%$, $S E M=18.5 \%$; Group $2 M=79.7 \%, S E M=20.6 \%)$, and was found not to be statistically significant, $t(10)=1.37, p=$ 0.20 . As a result, the counterbalance groups were combined for all further analyses.

\section{Phase 1: Spatial discrimination}

In Phase 1, on average, the pigeons showed a preference for the DRO schedule. The average proportion of DRO choices was $73.6 \%, S E M=11.0 \%$. However, as shown in the left bar for each subject in Fig. 2, individual differences are apparent, as the proportion of DRO choices ranged from $1 \%$ to $100 \%$. DRO preference was not significantly related to: the duration of the DRO schedule, $r(12)=.04, p=.91$; the number of pecks made during the DRO schedule, $r(12)=-.04, p=.91$; or the number of pecks made during the FI schedule, $r(12)=-.28$, $p=.37$. 


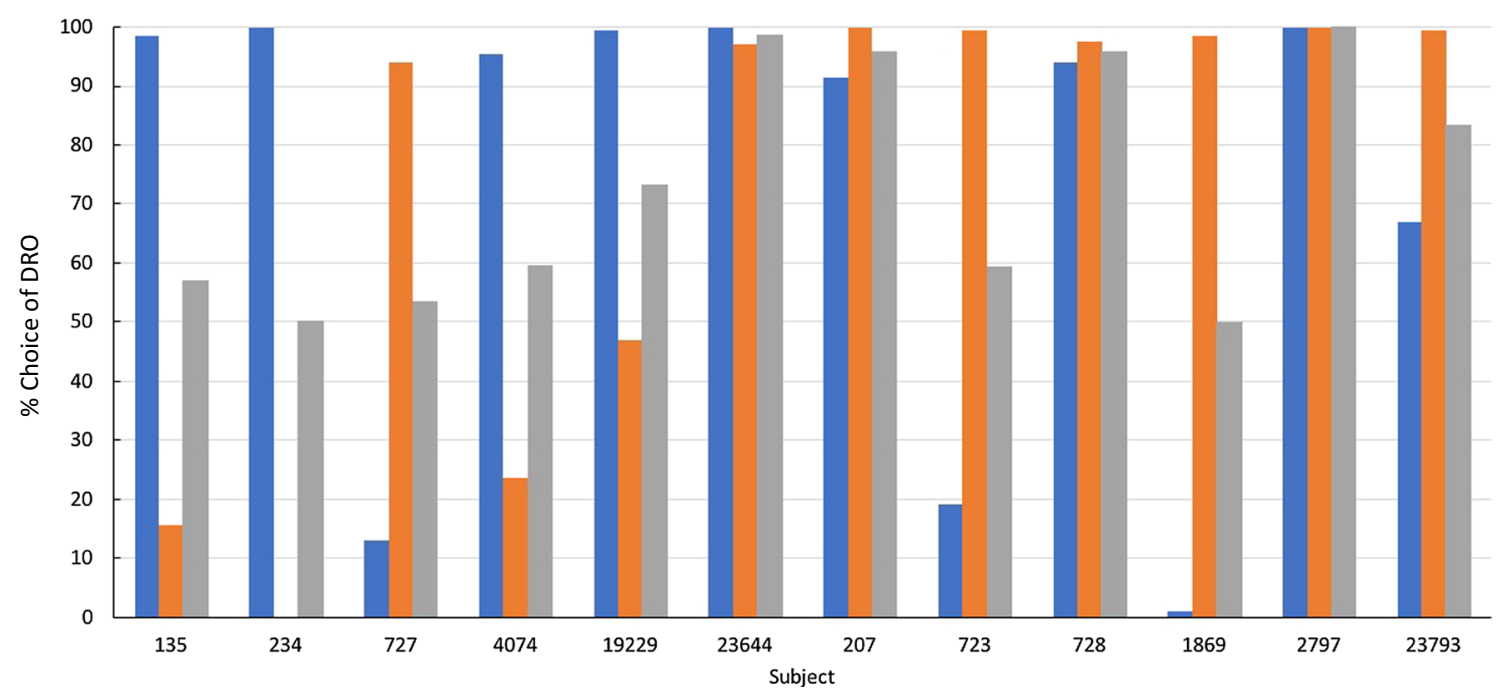

Fig. 2 Mean proportion of choices of the differential-reinforcement-of-other behavior (DRO) alternative for each subject during the last ten sessions of Phase 1 (left bar), Phase 2 (center bar), and the combined average of both phases (right bar)

During Phase 1, the average duration of DRO schedule ranged from 10.14 to $12.29 \mathrm{~s}, M=11.18, S E M=0.22$. The average number of DRO pecks was 0.69 per trial, $S E M=.13$. The average number of pecks during the FI schedule was 10.2, $S E M=2.03$, although the average number of pecks ranged from 1.6 to 26.7 pecks per trial. DRO pecks and the number of FI pecks were not significantly correlated, $r(12)=.50, p=.10$. As a manipulation check, on average, pigeons pecked more during the FI schedule $(M=10.2, S E M=2.03)$ than during the DRO schedule $(M=0.69, S E M=.13)$, and this difference was statistically significant, $t(11)=4.84, p<.001$, indicating that the schedules were effective in producing differential pecking.

\section{Phase 2: Reversal of the spatial discrimination}

In Phase 2, the discrimination reversal, once again on average the pigeons showed a preference for the DRO schedule. The average proportion of DRO choices during the last ten sessions of Phase 2 was $72.7 \%$, SEM $=11.3 \%$; however, this ranged from $0 \%$ to $100 \%$. As shown in Fig. 2 (in the middle bar for each subject), individual differences are apparent. Once again, Pearson correlations revealed no statistically significant relationship between DRO choice and DRO duration, $r(12)=-.23, p=.48$, between DRO choice and DRO pecks, $r(12)=-.07, p=.84$, or between DRO choice and FI pecks, $r(12)=.16, p=.63$.

The average duration of DRO trials was $10.92 \mathrm{~s}, S E M=$ 0.26 . The number of DRO pecks ranged from .05 to 1.68 , with an average of 0.59 pecks per trial, $S E M=.16$. The number of responses to the FI schedule ranged from 2.2 to 22.2 pecks per trial, $M=11.7, S E M=1.53$. DRO pecks and FI pecks were not significantly related, $r(12)=.30, p=.34$. Again, as a manipulation check, on average the pigeons pecked more during the FI schedule $(M=11.7, S E M=1.53)$ than during the DRO schedule $(M=.59$, SEM $=.16)$, and this difference was statistically significant, $t(11)=7.47, p<.001$.

\section{Phases 1 and 2: Spatial discriminations combined}

The average DRO choice proportion for each bird from Phases 1 and 2 combined provides a better indicator of schedule preference than either Phase 1 or 2 alone because it allows one to distinguish spatial bias from schedule preference. Individual subject data from Phases 1 and 2 combined are presented in the right bar for each subject in Fig. 2. A paired samples $t$-test indicated that there was no significant difference in the average DRO choice proportions between Phases 1 and 2; Phase $1 M=73.63 \%$, $S E M=11.04 \%$; Phase $2 M=72.67 \%, S E M=11.31 \%$; $t(11)=.05, p=.96$.

The average duration of the DRO schedule was not significantly different between Phases 1 and 2, $t(11)=1.24, p=.24$ and the number of DRO pecks was not significantly different between the two phases, $t<1$. Also, the number of responses during the FI schedule was not significantly different between the two phases, $t<1$.

Overall, six of the pigeons were classified as indifferent between the DRO and modified FI schedules. Of the remaining pigeons, six were classified as preferring the DRO schedule and none preferred the modified FI schedule.

\section{Phase 3: Visual discrimination}

As with the combined Phases 1 and 2, the results of Phase 3 indicated that there were clear individual differences. The average DRO choice proportion during the last ten sessions of Phase 3 ranged from $36.5 \%$ to $96.5 \%, M=69.5 \%$, SEM = $6.1 \%$. Pearson correlations between average choices of the 
DRO alternative and each average DRO duration, $r(12)=-.35$, $p=.27$, DRO pecks, $r(12)=-.12, p=.71$, and FI responses, $r(12)=.47, p=.13$, were not statistically significant.

The average duration of the DRO schedule was $10.6 \mathrm{~s}$, $S E M=.18$. The number of DRO pecks ranged from .07 to 1.42 per trial, $M=.42, S E M=.13$. The number of responses to the FI schedule ranged from 4.3 to $24.6, M=10.26, S E M=$ 1.62 .

A Pearson correlation between the average number of DRO pecks and the average number of pecks during FI trials during the last ten sessions was statistically significant, $r(12)=$ $.61, p=.04$. Once again, a paired samples $t$-test comparing the average number of DRO pecks $(M=.42, S E M=.13)$ and the average number of pecks to the FI schedule $(M=10.32, S E M$ $=1.60$ ) during the last ten sessions of Phase 3 indicated that there was a significant difference between the two, $t(11)=$ $6.37, p<.001$.

\section{All phases}

A repeated-measures analysis of variance revealed no statistically significant differences in the average number of DRO choices between phases, $F(2,22)=.05, p=.83$. Similarly, the proportion of DRO choices made across the last ten sessions of Phase 1 and Phase 2 together were highly correlated with the average proportion of DRO choices in Phase 3, $r(12)=$ $.94, p<.001$. The average DRO choice proportion for each subject during the last ten sessions of Phase 3 together with the average of Phases 1 and 2 together is shown in Fig. 3. Schedule preference and the duration of DRO schedule were not significantly correlated in any phase, Phase $1 r(12)=.04, p$ $=.91$; Phase $2 r(12)=-.23, p=.48$; Phase $3 r(12)=-.35, p=$ .27. Therefore, longer trials did not seem to affect preference.

A repeated-measures analysis of variance was computed to compare the average duration of the DRO schedule during the last ten sessions of each phase. There was a significant effect of phase on the average duration of the DRO trials; Phase $1 M$ $=11.2 \mathrm{~s}, S E M=.22 ;$ Phase $2 M=10.92 \mathrm{~s}, S E M=.26$; Phase 3 $M=10.6, S E M=.18 ; F(2,22)=4.00, p=.03$. Bonferroni post $h o c$ tests indicated that there was a significant difference between the average duration of the DRO schedule in Phase 1 compared to Phase $3, p=.01$. On average, the DRO durations in Phase $3(M=10.63 \mathrm{~s}, S E M=.18)$ were $0.55 \mathrm{~s}(S E M=.17)$ shorter than those in Phase $1(M=11.2 \mathrm{~s}$, $S E M=.22)$.

The DRO schedule required the pigeon to refrain from pecking for $10 \mathrm{~s}$; each time the pigeon pecked the DRO response key, the timer reset and as a result the trial lengthened by the time prior to the reset. All of the birds were still resetting the timer during DRO schedule during the last ten sessions of the experiment. A repeated-measures analysis of variance was computed to compare the average number of pecks to the DRO schedule during the last ten sessions of each phase, Phase $1 M=.69, S E M=.13$, Phase $2 M=.59$, SEM $=.16$, Phase $3 M=.42, S E M=.13$. There was not a significant effect of phase on the average number of DRO pecks, $F(2,22)$ $=1.53, p=.24$. The number of DRO pecks was not significantly correlated with schedule preference in any phase, Phase $1 r(12)=-.04, p=.91$; Phase $2 r(12)=-.07, p=.84$; Phase 3 $r(12)=-.12, p=.71$. Therefore, resetting the DRO schedule due to pecking did not appear to affect schedule preference. Given the relatively short mean extension of the DRO duration due to DRO pecking, it appears that most of those pecks occurred immediately after the onset of the DRO schedule. Some of those pecks were likely carryover or double pecks from the initial link choice of schedule.

The average number of DRO pecks and FI pecks was significantly correlated during Phase 3 , but not during Phases 1 and 2: Phase $1 \mathrm{r}(12)=.50, \mathrm{p}=.10$; Phase $2 \mathrm{r}(12)=.30, \mathrm{p}=.34$; Phase $3 r(12)=.61, p=.04$. The correlation between DRO

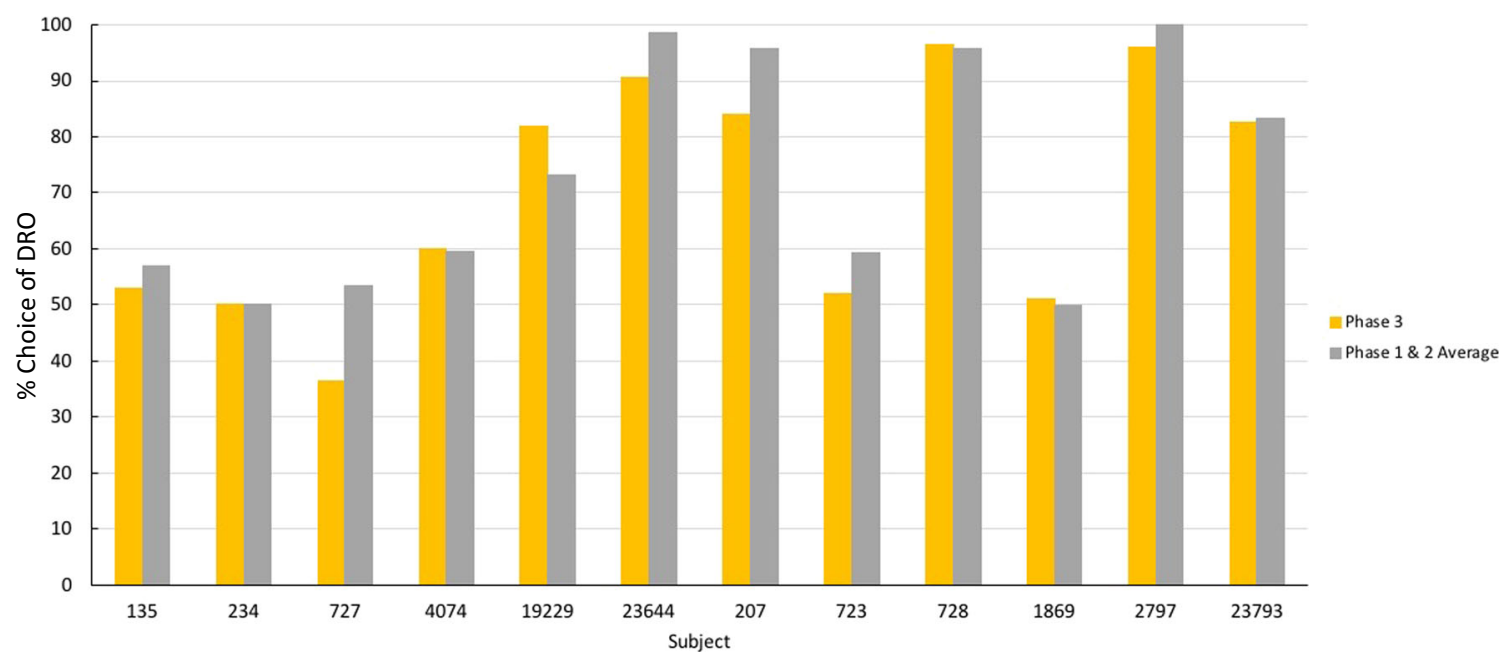

Fig. 3 The mean percentage of choices of the differential-reinforcement-of-other behavior (DRO) schedule for each subject during the last ten sessions of Phase 3 and the mean of the last ten sessions of Phases 1 and 2 combined 


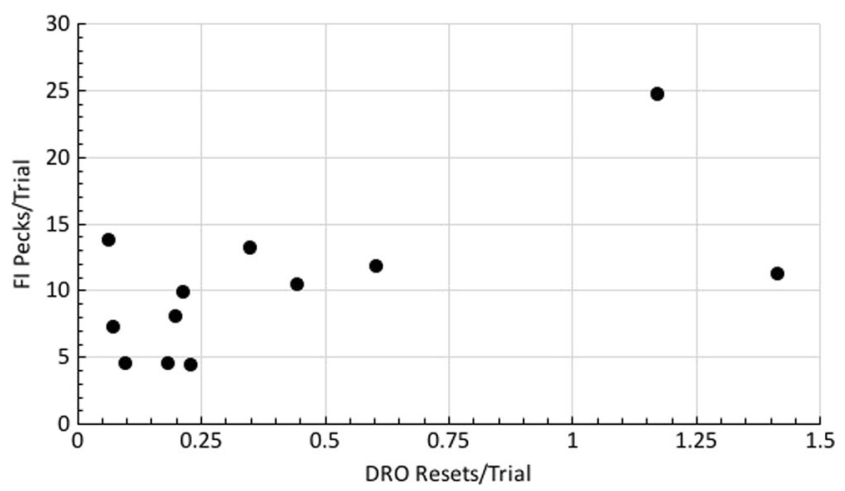

Fig. 4 The Pearson correlation between the mean number of differentialreinforcement-of-other behavior (DRO) resets per trial and the mean number of pecks to the fixed-interval (FI) schedule during the last ten sessions of Phase $3, r(12)=.61, p=.04$

pecks and FI pecks during the last ten sessions of Phase 3 is shown in Fig. 4.

A repeated-measures analysis of variance was computed to compare the average number of pecks to the FI schedule during the last ten sessions of each phase. There was not a significant effect of phase on the average number of FI pecks, $F(2,22)=.88, p=.38$. The average number of pecks during the FI schedule during the last ten sessions of each phase for each subject is shown in Fig. 5. The number of responses to the FI schedule was not significantly correlated with schedule preference in any phase, Phase $1 r(12)=-.28, p=.37$; Phase 2 $r(12)=.16, p=.63$; Phase $3 r(12)=.47, p=.13$. Therefore, once again, more pecking did not seem to affect schedule preference.

\section{Individual subject data and behavioral observations}

If a pigeon had a spatial preference that was greater than its schedule preference then the schedule preference would reverse in Phase 2. Most pigeons showed some level of disruption of their choices immediately following the reversal. However, with further training, pigeons that preferred the DRO in Phase 1 showed an increase in DRO choices in Phase 2. In Phase 3 the initial link visual discrimination controlled for possible spatial preference as the source of an apparent schedule preference. In this phase, the absence of a schedule preference was seen as a $50 \%$ choice of the DRO schedule.

In the present experiment, we interpreted a preference for the DRO schedule as an indication of a preference for the absence of effort. But of course, the absence of key pecking does not indicate what the pigeons are doing when they are not key pecking. For this reason, the pigeons were observed and, in particular, their behavior during the DRO schedule was noted. If during the DRO schedule the pigeons pecked somewhere else on the panel, pecked the key with insufficient force to operate the microswitch, or engaged in some other behavior that might be considered effortful, they may not have shown a schedule preference because they would have engaged in "effortful" behavior during both schedules (see Pinkston \& Libman, 2017). The relation between schedule preference and behavior during the DRO schedule is shown in Table 1, with subjects listed in order of their preference for the DRO schedule. As can be seen in the table, the behavior of the pigeons during the DRO schedule did not predict their preference for the DRO schedule.

\section{Discussion}

Although several of the pigeons preferred the DRO schedule over the FI schedule, the main finding of the experiment was clear individual differences in reinforcement schedule preference. Six birds showed a clear preference for the DRO

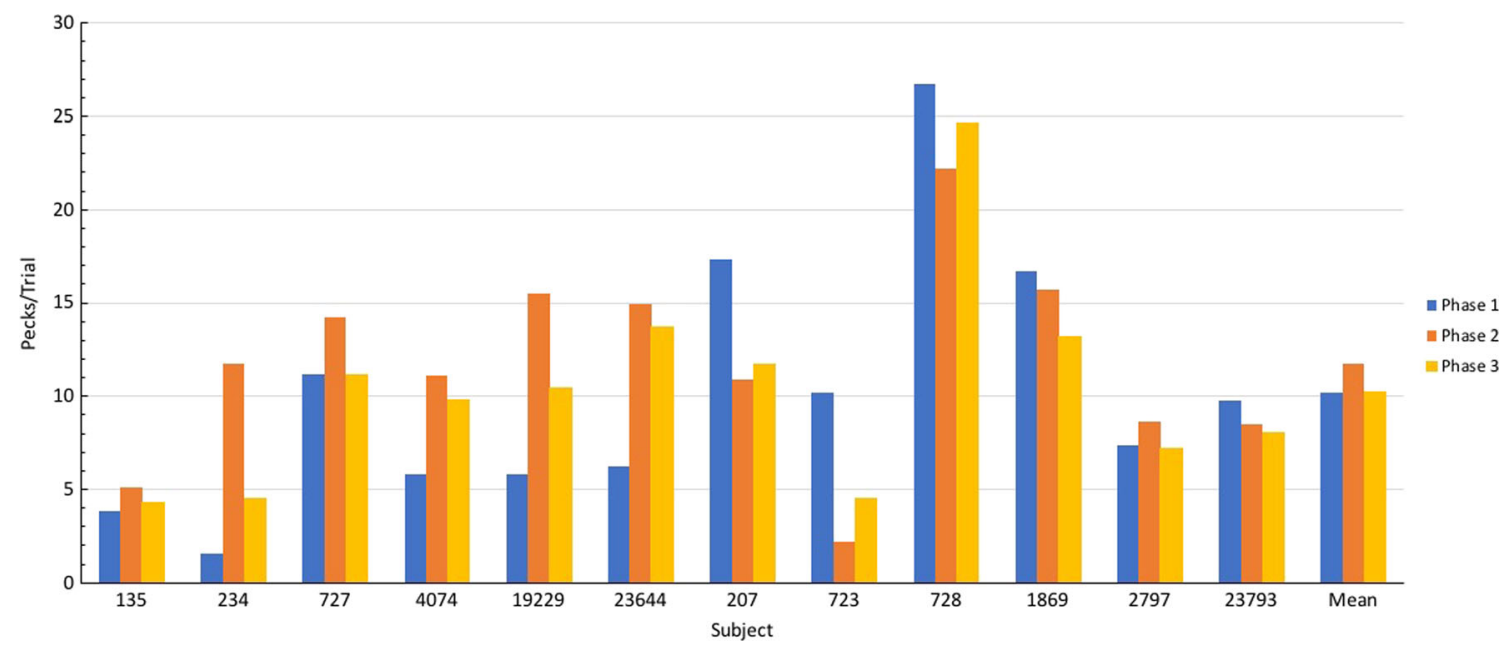

Fig. 5 Mean number of pecks made to fixed-interval (FI) schedule for each subject during the last ten sessions of each phase, Phase $1 M=10.21, S E M=$ 2.03, Phase $2 M=11.74, S E M=1.53$, Phase $3 M=10.26, S E M=1.62$ 
Table 1 Summary of observed behavior during DRO schedule and schedule preference during the last ten sessions of Phase 3

\begin{tabular}{|c|c|c|c|c|}
\hline Subject & Observed behavior & $\%$ DRO choice & Preference $^{\mathrm{a}}$ & $\begin{array}{l}\text { Behavior consistent } \\
\text { with choice? }^{\mathrm{c}}\end{array}$ \\
\hline 727 & $\begin{array}{l}\text { Waited during DRO. Looked at the hopper. Sometimes pecked the } \\
\text { response key with insufficient force }\end{array}$ & 36.5 & Indeterminate ${ }^{b}$ & --- \\
\hline 234 & Paced between response keys during DRO & 50.0 & Indifferent & No \\
\hline 1869 & Waited during the DRO & 51.0 & Indifference & No \\
\hline 723 & Moved to middle of panel during the DRO & 52.0 & Indifferent & No \\
\hline 135 & $\begin{array}{l}\text { Head-bobbed toward response key, or pecked key with insufficient } \\
\text { force to reset DRO }\end{array}$ & 53.0 & Indifferent & No \\
\hline 4074 & Pecked response key gently. Paced between keys & 60.0 & Indifferent & Yes \\
\hline 19229 & Pecked key with insufficient force. Waited during the DRO & 82.0 & $\mathrm{DRO}$ & No \\
\hline 23793 & Waited during the DRO. Pecked the floor & 82.5 & DRO & No \\
\hline 207 & Waited during the DRO and pecked key with insufficient force & 84.0 & DRO & Yes \\
\hline 23644 & $\begin{array}{l}\text { Waited with head bobbing toward key. Occasionally pecked unlit } \\
\text { center key. Checked hopper often }\end{array}$ & 90.5 & DRO & Yes \\
\hline 2797 & Waited near hopper. Occasionally pecked unlit keys & 96.0 & DRO & Yes \\
\hline 728 & Pecked at key with insufficient force. Paced between keys & 96.5 & DRO & No \\
\hline
\end{tabular}

Note. Observational data collected during one session immediately following completion of Phase 3

${ }^{a}$ DRO preference defined as $80 \%$ choice of DRO alternative or greater. Indifference defined as $40-60 \%$ choice of DRO alternative. FI preference defined as $20 \%$ choice of DRO alternative or less

${ }^{\mathrm{b}}$ Preference of \#727 considered indeterminate because percentage of DRO choice fell between criterion levels

${ }^{\mathrm{c}}$ Consistent behavior was considered waiting during the DRO if showing a DRO preference or pecking during the DRO if showing indifference between schedules

$D R O$ differential-reinforcement-of-other behavior

schedule over the FI schedule and six birds did not. Figures 2 and 3 show distinct preference subgroups within our sample.

Six pigeons were categorized as indifferent between the two schedules (or their spatial preference was more consistent than their schedule preference) as they chose the DRO schedule between $40 \%$ and $60 \%$ of times. One pigeon showed a preference in the direction of the FI schedule (36.5\% choice of the DRO schedule, but only in Phase 3), and it was the only pigeon observed to have any preference in that direction.

Individual differences in our data are in line with Singer, Berry, and Zentall (2007). Singer et al. found individual differences in schedule preference (DRO vs. FI) when the delay to reinforcement was controlled, as it was in the present experiment. Of the seven pigeons in their sample, four were indifferent with regard to the two schedules, one preferred the FI schedule, and two preferred the DRO schedule. Thus, they found that most of their pigeons did not prefer to avoid pecking and one actually showed a preference for pecking, whereas in the present experiment half of the pigeons preferred to refrain from pecking.

Preference for the DRO schedule is surprising because the DRO schedule is typically more difficult to learn, considering that maintained pecking on DRO schedules tends to occur even though those pecks are never associated with reinforcement (Williams \& Williams, 1969). Given the fact that pigeons will naturally peck at stimuli that are followed by reinforcement (sign-tracking or Pavlovian conditioning), it may be considered "effortful" for pigeons to avoid pecking at the stimulus signaling the DRO schedule.

Also, although the schedules were matched for their duration on a trial-by-trial basis, the relation between DRO pecking and lengthening the duration of the DRO trial should be easier to detect than the effect of DRO pecking on the equated duration of the next FI schedule because extension of the FI schedule due to DRO pecking would have been delayed to the next trial. Thus, it should have been more difficult for the pigeons to attribute the longer FI schedules to pecking during the DRO schedule. This should have increased the pigeons' tendency to prefer the FI schedule, yet none was found.

Pigeons that were indifferent to the two schedules provide support for the idea that schedule preference is a function of the delay to reinforcement rather than the response requirements associated with the schedule. Indifference to reinforcement schedules in pigeons has been reported in past experiments. For example, despite very different response requirements when attempting to control for the delay of reinforcement, Killeen (1968) found that pigeons were indifferent to the two schedules. Similarly, Neuringer (1969) found no differential preference between FI and FT schedules when the duration of inter-reinforcement intervals was controlled. Moore and Fantino (1975) also found that pigeons were 
indifferent to response-dependent and response-independent schedules of similar durations.

Individual differences were evident in response rates during the FI schedule, and in the number of pecks made during the DRO schedule that reset the timer (DRO pecks). Response rates varied between subjects but did not vary over the experimental phases. During Phase 3, the number of DRO pecks was positively correlated with the number of responses to the FI schedule. This finding suggests another individual difference among the subjects; however, it was observed only in Phase 3. This result may reflect an individual difference in the general tendency to peck, although it did not appear to affect schedule preference. Pigeons that are more active or impulsive, in general, may be those that peck the keys more frequently. Other pigeons may have performed better during the DRO and were able to refrain from pecking but they also did not peck as often during the FI. Because we found that the number of responses made during the DRO schedule that reset the timer (DRO pecks) and the number of responses during the FI schedule were correlated, it may be worth investigating whether response rate is a stable characteristic that could be associated with impulsivity. It would be of interest to know if pecking during the DRO or FI schedules is related to impulsivity as assessed by the slope of delay discounting function (Ainslie, 1975) or by the tendency to engage in suboptimal choice when low probability of reinforcement alternatives reliably signal those reinforcements following choice (Laude, Beckmann, Daniels, \& Zentall, 2014).

We also found that schedule preference was not related to the duration of the DRO schedule, the number of DRO pecks, or the number of responses to the FI schedule. The ability to withhold pecking during the DRO schedule did not appear to be related to the preference for the DRO schedule. One might have expected that pigeons that continued to reset the DRO timer, and as a result continued to increase the delay to reinforcement, would not have preferred the DRO schedule. However, the schedules were matched in duration on a trialby-trial basis, thus the delay to reinforcement would have remained the same for the following FI trial.

We had expected that the pigeons' behavior during the DRO schedule would predict their schedule preference; pigeons that were pecking somewhere other than the response keys or were engaged in some other active behavior might show indifference between the two schedules because effort would not have been clearly differential. By and large, this did not appear to be the case, as for most of the pigeons there was little relation between DRO behavior and the absence of a schedule preference.

\section{Potential limitations}

Due to the design of the study, DRO trials always preceded FI trials. This may have biased the pigeons toward choosing the
FI alternative on choice trials because the FI schedule would have appeared in the same location as the lit key on the previous trial; however, we did not find any clear FI schedule preference to suggest such a bias had an influence on choice behavior. Of course, one could also posit the opposite effect. The fact that the pigeons always switched keys between the first and second trials of the three-trial sequence may have encouraged them to switch back to the first side after the second trial of the sequence. The fact that the preferences persisted in Phase 3 when the discrimination was no longer based solely on the spatial location of the schedules suggests that the key-switching hypothesis is less likely to be correct.

\section{Conclusions}

Overall, we found large individual differences in the preference for differential-reinforcement-of-other-behavior (DRO) and fixed-interval (FI) reinforcement schedules that were matched in duration. Half of the pigeons in our sample $(\mathrm{n}=$ 6) showed a preference for the DRO schedule, whereas five pigeons were indifferent, and one showed a weak preference in the direction of the FI schedule. The pigeons that were indifferent with regard to the two schedules provide support for the hypothesis that preference is a function of the delay of reinforcement, rather than the response requirements associated with the schedule, while preference for the DRO schedule supports the Principle of Least Effort (Gengerelli, 1930; Tsai, 1932; Waters, 1937). Furthermore, we found that schedule preference was not related to the duration of the DRO schedule due to resets, the number of DRO pecks, the number of responses to the FI schedule, nor the behavior of the pigeons during the DRO schedule.

Publisher's note Springer Nature remains neutral with regard to jurisdictional claims in published maps and institutional affiliations.

\section{References}

Ainslie, G. (1975). Specious reward: A behavioral theory of impulsiveness and impulse control. Psychological Bulletin, 82, 463-496.

Brinker, R. P., \& Treadway, J. T. (1975). Preference and discrimination between response dependent and response-independent schedules of reinforcement. Journal of the Experimental Analysis of Behavior, 24(1), 73-77.

Clement, T. S., Feltus, J., Kaiser, D. H., \& Zentall, T. R. (2000). 'Work ethic' in pigeons: Reward value is directly related to the effort or time required to obtain the reward. Psychonomic Bulletin \& Review, 7, 100-106.

Fantino, E. (1968). Effects of required rates of responding upon choice. Journal of the Experimental Analysis of Behavior, 11(1), 15-22.

Gengerelli, J. A. (1930). The principle of maxima and minima in animal learning. Journal of Comparative Psychology, 11(2), 193. 
Hearst, E. (1987). Extinction reveals stimulus control: Latent learning of feature-negative discriminations in pigeons. Journal of Experimental Psychology: Animal Behavior Processes, 13(1), 5264.

Herrnstein, R. J. (1964). Secondary reinforcement and the rate of primary reinforcement. Journal of Experimental Analysis of Behavior, 7, 2736.

Herrnstein, R. J., \& Morse, W. H. (1957). Some effects of responseindependent positive reinforcement on maintained operant behavior. Journal of Comparative and Physiological Psychology, 50(5), 461.

Hinnenkamp, J. E., Shahan, T. A., \& Madden, G. J. (2017). How suboptimal is suboptimal choice? Journal of the Experimental Analysis of Behavior, 107(1), 136-150.

Killeen, P. (1968). Response rate as a factor in choice. Psychonomic Science, 12(1), 34-34.

Laude, J. R., Beckmann, J. S., Daniels, C. W., \& Zentall, T. R. (2014). Impulsivity affects gambling-like choice by pigeons. Journal of Experimental Psychology: Animal Behavior Processes, 40, 2-11.

Moore, J., \& Fantino, E. (1975). Choice and response contingencies. Journal of the Experimental Analysis of Behavior, 23(3), 339-347.

Neuringer, A. J. (1969). Delayed reinforcement versus reinforcement after a fixed interval. Journal of the Experimental Analysis of Behavior, 12(3), 375-383.

Pinkston, J. W., \& Libman, B. M. (2017). Aversive functions of response effort: Fact or artifact?. Journal of the Experimental Analysis of Behavior, 108, 73-96.
Reynolds, G. S. (1961). Behavioral contrast. Journal of the Experimental Analysis of Behavior, 4(1), 57-71.

Singer, R. A., Berry, L. M., \& Zentall, T. R. (2007). Preference for a stimulus that follows a relatively aversive event: contrast or delay reduction? Journal of the Experimental Analysis of Behavior, 87(2), 275-285.

Stagner, J. P., \& Zentall, T. R. (2010). Suboptimal choice behavior by pigeons. Psychonomic Bulletin \& Review, 17(3), 412-416.

Tatham, T.A. \& Zurn, K.R. (1989). The Med-PC experimental apparatus programming system. Behavior Research Methods, Instruments, and Computers, 21, 294-302.

Tsai, L. S. (1932). The laws of minimum effort and maximum satisfaction in animal behavior. National Research Institute of Psychology.

Waters, R. H. (1937). The principle of least effort in learning. The Journal of General Psychology, 16(1), 3-20.

Williams, D. R., \& Williams, H. (1969). Auto-maintenance in the pigeon: sustained pecking despite contingent non-reinforcement. Journal of the Experimental Analysis of Behavior, 12(4), 511-520.

Zentall, T. R., \& Singer, R. A. (2008). Required pecking and refraining from pecking alter judgments of time by pigeons. Learning \& Behavior, 36(1), 55-61.

Zentall, T. R., \& Laude, J. R. (2013). Do pigeons gamble? I wouldn't bet against it. Current Directions in Psychological Science, 22(4), 271-277. 